\title{
Effect of bioactive glass nanoparticles on biological properties of PLGA/collagen scaffold
}

\author{
Samira Nokhasteh ${ }^{1} \cdot$ Alireza Sadeghi-avalshahr ${ }^{1} \cdot$ Amir Mahdi Molavi $^{1} \cdot$ Mohammad Khorsand-Ghayeni $^{1}$. \\ Hojjat Naderi-Meshkin ${ }^{2}$
}

Received: 21 December 2017 / Accepted: 28 April 2018 / Published online: 11 May 2018

(c) The Author(s) 2018

\begin{abstract}
Bioactive glasses have shown some interesting biological properties such as biocompatibility, biodegradation, and angiogenesis in skin tissue engineering. In the current research, the effects of $\mathrm{MgO}$ - or $\mathrm{CoO}$-doped $64 \mathrm{~S}$ bioactive glass with a composition of $64 \mathrm{SiO}_{2}-26 \mathrm{CaO}-5 \mathrm{P}_{2} \mathrm{O}_{5}-5 \mathrm{MgO}$ or $\mathrm{CoO}$ (mol\%) were studied in relation with biological properties of electrospun [poly(lactic-co-glycolic acid) (PLGA)/collagen]. PLGA/collagen samples were rinsed in suspension of bioactive glass nanoparticles in distilled water with a concentration of $0.1 \mathrm{w} / \mathrm{v}$ and then freeze dried. Cell adhesion, viability, angiogenesis, and ionic release were performed and tested in culture medium containing fibroblast cells. Attachment and viability of fibroblast cells were increased significantly in bioglass-coated samples, while shrinkage in PLGA/collagen scaffold was reduced by the addition of bioactive glass. Vascular endothelial growth factor secretion in coated scaffold was dropped compared to the uncoated samples. This could be attributed to the fast degradation of glass nanoparticles, according to the inductively coupled plasma-atomic emission spectroscopy results.
\end{abstract}

Keywords $64 \mathrm{~S}$ bioactive glass $\cdot$ PLGA/collagen $\cdot$ Ionic release $\cdot$ Skin substitute

\section{Introduction}

Since the introduction of bioactive glasses in 1969 , these materials have attracted a wide attention for tissue engineering applications. Bioactive glass (BG) or simply bioglass is a non-crystalline solid material, which consists of various oxides. Each oxide plays a specific role in the glass structure, and depending on the glass formation ability, they are divided into three categories: glass or network forming site, network modifier, and intermediate oxide. To degrade

Electronic supplementary material The online version of this article (https://doi.org/10.1007/s40204-018-0089-y) contains supplementary material, which is available to authorized users.

Amir Mahdi Molavi

mahdi.molavi@jdm.ac.ir

1 Department of Materials Research, Iranian Academic Center for Education, Culture and Research (ACECR), Mashhad Branch, Mashhad 91775-1376, Iran

2 Stem Cell and Regenerative Medicine Research Department, Iranian Academic Center for Education, Culture and Research (ACECR), Mashhad Branch, Mashhad 91775-1376, Iran in contact with body fluids, the composition of BG is normally selected in a way which provides a poor chemical strength (Rahaman et al. 2011). During glass degradation, some events such as exchange and release of ions, formation of gel-like film on the glass surface, accumulation of ions, and nucleation of apatite crystals on the surface provide conditions for osteo-conduction as well as osteo-induction (Gerhardt and Boccaccini 2010). Although most research of bioactive glasses has been performed on hard tissues, these materials are also able to bond with soft tissues (Hench 2006). The potential application of bioactive glasses for wound healing has been reviewed by Naseri et al. (2017). In general, the advantages of bioactive glasses include bonding to both hard and soft tissues, biodegradability, improving adhesion, as well as proliferation and differentiation of cells, high compositional flexibility due to utilizing useful cations for tissue restoration, and angiogenesis (Hench 2006; Rahaman et al. 2011). The capability of using various ions in the composition of bioglasses gives them some favorable properties such as antibacterial, blood coagulation, and healing acceleration (Bellantone et al. 2002; Ostomel et al. 2006; Miola and Verné 2016). In addition to the above-mentioned advantages, bioactive glasses can improve angiogenesis. One 
requirement for successful application of engineered scaffold is the development of new blood vessels, i.e., angiogenesis. If neovascularization does not occur in a three-dimensional scaffold, the viability of cells would be restricted due to lack of oxygen and nutrients. One solution is to approach using growth factors, although application of these proteins is not possible because they are destroyed under the temperature or chemical solutions, which are inevitable parts of scaffold fabrication. Therefore, angiogenesis is considered as one of the most important properties of bioactive glasses.

A 64S bioactive glass is a silicate-based glass with a composition of $64 \mathrm{SiO}_{2}-31 \mathrm{CaO}-5 \mathrm{P}_{2} \mathrm{O}_{5}$ (mol\%). Bioactivity and biological properties of this glass have been investigated in some research works (Saboori et al. 2009; Imani Fooladi et al. 2013). Divalent oxides such as $\mathrm{ZnO}, \mathrm{SrO}$, and $\mathrm{MgO}$ can also be substituted partially with $\mathrm{CaO}$ to improve the biological properties of the glass (Balamurugan et al. 2007; Gentleman et al. 2010). For example, $\mathrm{MgO}$ has been reported to be effective in angiogenesis by inducing nitric oxide production in endothelial cells (Bose et al. 2013). A comprehensive review on $\mathrm{Mg}$-containing bioactive glasses for biomedical application has been published by Diba et al. (2012). Also, it has been indicated that $\mathrm{CoO}$ can improve angiogenesis by inducing hypoxia condition. Hypoxia can activate hypoxia-inducible factor 1 (HIF-1), which is an important factor for the development of angiogenesis (Bose et al. 2013).

Despite these interesting and useful properties, the use of bioactive glasses is restricted due to their brittleness. To solve this problem, the combination of BG with biopolymers could be beneficial. In our previous work, we synthesized and investigated the properties of collagen-coated poly(lactic-co-glycolic acid) (PLGA) fibrous scaffold for skin tissue engineering applications (Sadeghi et al. 2016). Collagen is the main structural protein in the extracellular matrix which is biocompatible, biodegradable, and has shown wound-healing properties ( $\mathrm{Li}$ et al. 2002; Rho et al. 2006; Chen et al. 2008; POWELL et al. 2008). PLGA is a biodegradable poly( $\alpha$-hydroxyester), which possesses better mechanical properties than natural polymers such as collagen (Dhandayuthapani et al. 2011). In the present study, we aim to add BG to the above-mentioned scaffold to improve its biological properties.

Boccaccini and Maquet fabricated PLGA/Bioglass ${ }^{\circledR}$ by thermally induced phase separation (TIPS) method and with different percentages of bioactive glass at maximum $50 \mathrm{wt} \%$. They showed that the addition of BG to the scaffold increases water absorption and has a buffering effect, which may prevent inflammatory response toward acidic degradation of PLGA (Boccaccini 2003). Blaker et al. fabricated PDLLA and PDLLA/Bioglass ${ }^{\circledR}$ by TIPS method and showed better bioactivity, viability, and attachment of osteoblast cells to the composite scaffold compared to PDLLA alone
(Blaker et al. 2003). Liverani et al. incorporated $30 \mathrm{wt} \%$ of BG with respect to PCL weight percentage in electrospun PCL/chitosan scaffold (Liverani et al. 2018). They detected no HCA peak in XRD analysis after 7 days of immersion in SBF solution. Composites of polypeptide poly(N3-Cbz-L-lysine) (PZL)/PLGA with sol-gel-derived 45S5 bioglass were synthesized using negative NaCl-templating method (Cui et al. 2016). In vitro tests indicated that the addition of BG enhances adhesion, spreading, and proliferation of MC3T3E1 cells, as well as inducing MC3T3-E1 differentiation to osteoblasts cells. Also the incorporation of sol-gel-derived BG into PLGA scaffold caused osteo-inductive properties and improved mechanical properties after incubation in SBF (Filipowska et al. 2014). Significant increment in the secretion of vascular endothelial growth factor (VEGF) from CCD-18Co myofibroblast (Keshaw et al. 2009) and L929 fibroblast (Day et al. 2005) has been reported for PLGA containing 45S5 Bioglass ${ }^{\circledR}$ compared to a neat PLGA. Moreover, it has been observed that this effect (i.e., stimulation of angiogenic growth factors) is dose dependent, and high concentration of BG has a negative effect on growth factor secretion. Besides biological properties, surface coating of electrospun PLGA fibers with mesoporous bioactive glass improved the capability of scaffold for BMP-2 delivery ( $\mathrm{Li}$ et al. 2015). Addition of BG to collagen has been studied in some research. Enhanced proliferation of human microvascular endothelial cells (HMVEC) and greater VEGF mRNA production was observed by the addition of specific amounts of glass to the collagen sponge (Leu and Leach 2008). Nanosized bioactive glass (nBG) with particle size in the range of 20-30 nm was added to bovine type I collagen film; composites containing $10 \mathrm{wt} \% \mathrm{nBG}$ enhanced angiogenesis, while its $20 \mathrm{wt} \%$ hindered this property (Vargas et al. 2013). Wheeler et al. compared elastin-like polypeptides (ELP)collagen and ELP-bioglass-collagen composites; they found that mechanical properties and ALP activity increased by the addition of bioglass (Wheeler et al. 2013).

Although the bioactive glass addition to collagen and PLGA has been studied separately, to the best of our knowledge, no research has investigated the effect of bioactive glass addition to the PLGA/collagen composite scaffold. Therefore, in this study, we are conducting a set of experiments in vitro to observe the effects of Co- or Mg-doped 64S bioactive glass on biological properties of PLGA/collagen fibrous scaffold.

\section{Materials and methods}

\section{Materials}

$\mathrm{MgO}$ - and CoO-doped 64S bioactive glasses with particle size of $20-50 \mathrm{~nm}$ were acquired in the Baqiyatallah Research 
Center (Tehran, Iran). The bioactive glasses were synthesized by the sol-gel method according to the literature (Imani Fooladi et al. 2013). The compositions of the two type bioactive glasses are shown in Table 1. MTT (3-[4,5-dimethylthiazol-2-yl]-2,5 diphenyltetrazolium bromide) and phosphatebuffered saline (PBS) were purchased from Sigma-Aldrich. Dimethylsulfoxide (DMSO), Dulbecco's modified Eagle medium (DMEM), and fetal bovine serum (FBS) were prepared from Invitrogen (Germany).

\section{Fabrication of coated scaffold}

Collagen-coated PLGA electrospun fibers were produced with a thickness of approximately $0.2 \mathrm{~mm}$ according to the authors' previous work (Sadeghi et al. 2016). In brief, $20 \mathrm{w} / \mathrm{v} \%$ of PLGA was dissolved in DMF/THF with a ratio of 1:3 and stirred for $12 \mathrm{~h}$. Fabrication of scaffold was conducted by electrospinning machine (ANSTCO-RN/I, Iran). The obtained PLGA mats were hydrolyzed with $0.1 \mathrm{~N}$ concentration of $\mathrm{NaOH}$ to produce hydroxyl and carboxyl groups on the fibers' surface. The activated fibers were immersed in a $2 \mathrm{mg} / \mathrm{mL}$ collagen solution in acetic acid (\% 0.5 by volume) for $5 \mathrm{~h}$ at $4{ }^{\circ} \mathrm{C}$ temperature. The cross-linking process was carried out using EDC/NHS (4/1) in 0.05 M MES.

PLGA/collagen samples were cut in 12-well plate size and sterilized on both sides. For coating with bioactive glass, slurry of $0.1(\mathrm{w} / \mathrm{v}) \mathrm{BG}$ nanoparticles was prepared in distilled water. After ultrasonication for $30 \mathrm{~min}$, each slurry sample was poured into the 12-well polystyrene tissue culture plates. The plates were air dried in a laminar air hood. Different samples, including PLGA/collagen scaffold without bioactive glass, scaffold coated with Mg-doped bioactive glass, and scaffold coated with Co-doped bioactive glass were named uncoated, BG-Mg, and BG-Co, respectively.

\section{Characterization}

All characterizations were carried out on PLGA/collagenuncoated scaffold and 64S bioglass-coated scaffolds (BG-Mg and BG-Co).

\section{MTT assay}

The disc-shaped scaffolds with a diameter of $20 \mathrm{~mm}$ were sterilized by UV for $20 \mathrm{~min}$. After soaking in sterile PBS (pH 7.4) for $2 \mathrm{~h}$, the samples were placed in a 12-well plate in

Table 1 Compositions of bioactive glasses in mol\%

\begin{tabular}{llllll}
\hline & $\mathrm{SiO}_{2}$ & $\mathrm{CaO}$ & $\mathrm{P}_{2} \mathrm{O}_{5}$ & $\mathrm{MgO}$ & $\mathrm{CoO}$ \\
\hline Mg-doped BG & 64 & 26 & 5 & 5 & - \\
Co-doped BG & 64 & 26 & 5 & - & 5 \\
\hline
\end{tabular}

triplicate and 3T3 fibroblast cell lines were seeded into the 12 -well cell culture plates $\left(2 \times 10^{4}\right.$ cells/well). The suspensions were cultured in DMEM with $10 \% \mathrm{FBS}$ and $100 \mathrm{U} \mathrm{mL}^{-1}$ penicillin $/ 100 \mu \mathrm{gmL}^{-1}$ streptomycin, and incubated in $5 \% \mathrm{CO}_{2}$ at $37^{\circ} \mathrm{C}$. Cell proliferation was assessed after 24,48 , and $72 \mathrm{~h}$ by the addition of MTT solution to culture medium. After incubation for $2 \mathrm{~h}$, MTT reaction medium was removed and $550 \mu \mathrm{L}$ DMSO was added to each well. Elisa plate reader (ELX808, Biotek) measured the absorbance at $570 \mathrm{~nm}$. The cell viability was calculated after subtraction of OD from the scaffolds without cell seeding.

\section{Cell adhesion}

Circular discs of scaffolds coated with $\mathrm{CoO}$ or $\mathrm{MgO} 64 \mathrm{~S}$ bioglasses were prepared, sterilized, and seeded in triplicates with $3 \mathrm{~T} 3$ fibroblast cells $\left(2 \times 10^{4}\right.$ cells $\left./ \mathrm{ml}\right)$ and cultured in a 12-well plate as mentioned above. The plates were incubated for 3 days in $5 \% \mathrm{CO}_{2}$ at $37{ }^{\circ} \mathrm{C}$. After incubation, the culture plates containing scaffolds were washed three times with PBS to remove the unattached cells. Attached cells were fixed in $2.5 \%$ glutaraldehyde solution for $3 \mathrm{~h}$. Thereafter, the scaffolds were rinsed twice in distilled water and dehydrated with high concentrations of ethanol for $15 \mathrm{~min}$. After drying in a desiccator, the samples were sputter coated with gold and evaluated by scanning electron microscope (LEO 1450VP).

\section{Angiogenesis evaluation}

The amount of VEGF secreted by $3 \mathrm{~T} 3$ fibroblast cells was assessed using supernatant of cell culture after 24, 48, and $72 \mathrm{~h}$. The measurements were carried out by quantitative enzyme-linked immunosorbent assay (ELISA) according to the manufacturer's instructions (Mouse VEGF Quantikine ELISA Kit; R\&D Systems, UK). The optical density of each well was determined using a microplate reader at a wavelength of $450 \mathrm{~nm}$. The results are presented in $\mathrm{pg} / \mathrm{mL}$ of VEGF. The values for secreted VEGF are expressed after subtraction of the amount of VEGF measured in culture medium plus $10 \%$ FBS without cells.

\section{ICP-OES}

To determine the concentration of released ions in culture medium, supernatants in three different durations $(24,48$, and $72 \mathrm{~h}$ ) were collected with three replications. The samples were diluted by $10 \%(\mathrm{v} / \mathrm{v})$ nitric acid; the supernatants to nitric acid ratio were $1: 10$. Ion concentrations of $\mathrm{Ca}$, $\mathrm{Co}, \mathrm{Mg}, \mathrm{P}$, and $\mathrm{Si}$ were measured by inductively coupled plasma-atomic emission spectroscopy (ICP-OES; Spectro Arcos, Germany). 


\section{Statistical analysis}

Data from MTT, VEGF, and ICP-OES tests were represented as mean \pm standard deviation and statistically analyzed by one-way analysis of variance (ANOVA). $p$ value $<0.05$ was set as statistically significant.

\section{Results}

\section{Microstructure and porosity of PLGA/collagen scaffold}

Figure 1 depicts microstructure, fiber diameter, and pore diameter frequency distribution histograms of PLGA/collagen scaffold. The SEM image shows beadles and approximately uniform fibrous scaffold. The fiber diameter lies in the range of 600-1300 nm, and the average diameter of fibers is $965 \mathrm{~nm}$. In addition, the result of mercury porosimetry demonstrates that the pore diameter is in the range of 4-30 $\mathrm{m}$ with an average of $11.3 \mathrm{~m}$.

\section{Cell attachment}

Fibroblast attachment after 3 days is shown in Fig. 2a-f for BG-coated and uncoated scaffolds. SEM images show that BG nanoparticles have been agglomerated during the coating process and they range from nanometer to micrometer. It is obvious that more cells have attached on the scaffolds coated with bioactive glasses.

\section{MTT assay}

Figure 3 shows the results of MTT assay for PLGA/ collagen-uncoated scaffold and the bioactive glasscoated scaffolds, i.e., BG-Co and BG-Mg. The viability of cells increased for all samples during 3 days. Also, no significant difference in the viability of cells can be observed between uncoated and BG-coated samples at $24 \mathrm{~h}$ of fibroblast culturing. However, after 48 and $72 \mathrm{~h}$, it is clear that the OD absorbance for both BG-Co and BG-Mg samples is significantly higher than uncoated sample. There is not any difference in OD between BG-Mg and BG-Co except on the third day; BG-Co shows a higher population of viable fibroblast cells after $72 \mathrm{~h}$.

\section{VEGF secretion}

Figure 4 represents secreted vascular endothelial growth factor from fibroblast cells. The amount of VEGF in all samples has increased significantly by increasing the time. It can be seen that the amount of VEGF secretion of uncoated sample is much higher than BG-coated scaffolds during different periods of the experiment. Comparing BG-Co sample with that of BG-Mg, no significant difference can be recorded.

\section{Ion release measurement}

$\mathrm{Si}, \mathrm{Ca}$, and $\mathrm{P}$ concentrations in culture medium for 24 , 48 , and $72 \mathrm{~h}$ are given in Fig. 5a-c. The concentration of $\mathrm{Si}$ for uncoated sample is far less than that of BG-coated samples. Conversely, the concentration of phosphorus for uncoated sample is higher than BG-coated samples at all 3 days. In the case of $\mathrm{Ca}$, the uncoated sample has the lowest concentration compared to BG-coated samples on day 1 , but it has the highest concentration on days 2 and 3 . Figure 6 shows magnesium and cobalt concentrations at different times for BG-Mg and BG-Co samples, respectively. The concentration of $\mathrm{Mg}$ increased at day 2, but then decreased, while the concentration of Co decreased at second day and then started increasing.
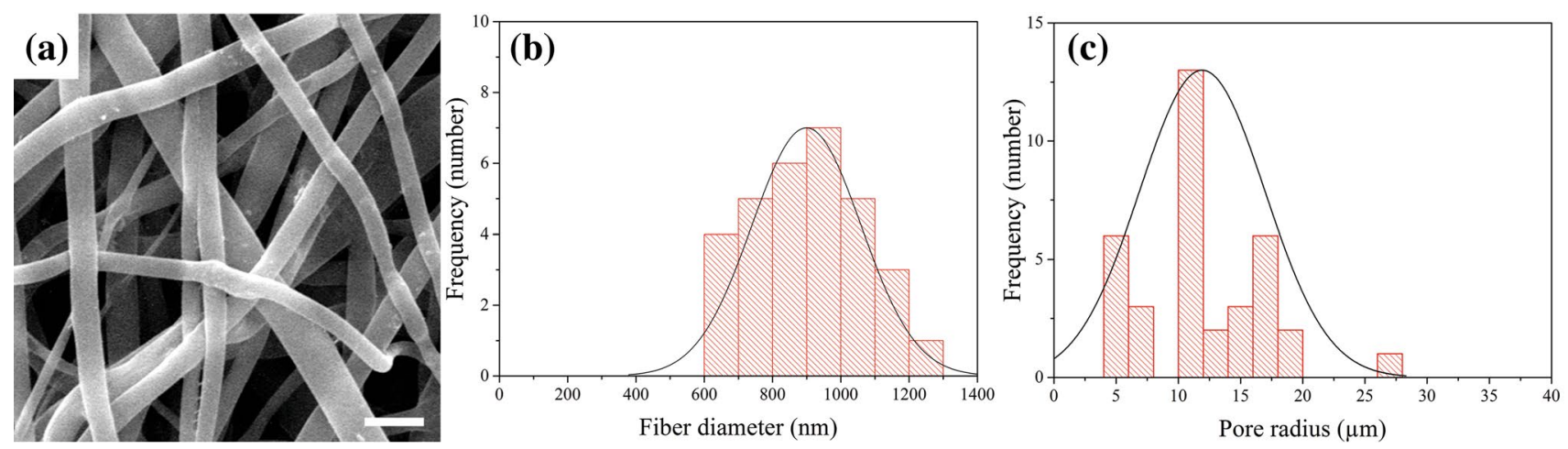

Fig. 1 a SEM image of scaffold comprising collagen-coated PLGA electrospun fibers; the scale bar shows $2 \mu$ m. b Histogram diagram of fiber diameter and $\mathbf{c}$ pore size distribution of the scaffold 

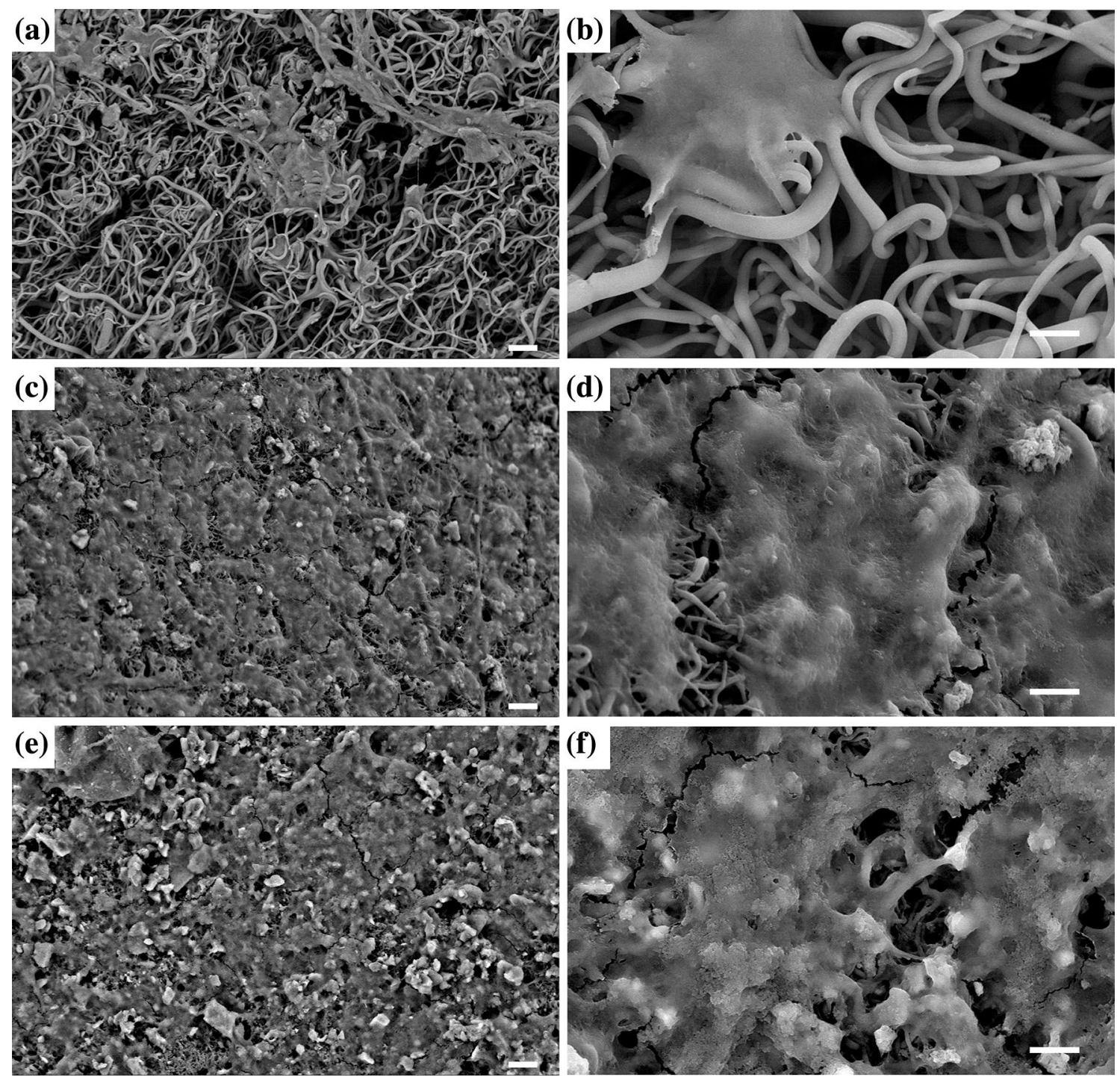

Fig. 2 SEM images with two magnifications for fibroblast attachment to: a, b PLGA/collagen scaffold; c, d scaffold coated with Mg-doped bioactive glass (BG-Mg); and e, f scaffold coated with Co-doped bio-

active glass (BG-Co). The scale bars for images a, $\mathbf{c}$, and $\mathbf{e}$ represent $20 \mu \mathrm{m}$ and for images $\mathbf{b}, \mathbf{d}$, and $\mathbf{f}$ represent $5 \mu \mathrm{m}$

\section{Discussion}

The microstructure of a scaffold, especially pore structure and fiber diameter, has a very important influence on cell adhesion, proliferation, migration, and differentiation. For cell nutrition, scaffolds should possess a porous structure with interconnected pores. The diameter of pores should not be too small to restrict the migration of cells into the pores and it should not be too large to limit cell adhesion due to large bridging distances across the pores (Lowery et al. 2010). Also, fiber diameter influences attachment, spreading morphology, and proliferation of cells (Kumbar et al. 2008; Hodgkinson et al. 2014; Li et al. 2016). The obtained fiber diameter for the synthesized PLGA/collagen scaffold (Fig. 1b) is in good agreement with Kumbar

et al. findings, which showed that the best fiber diameter for fibroblast attachment to PLGA scaffold was in the range of 350-1100 nm (Kumbar et al. 2008). Figure 2a, b illustrates well-spread and flattened morphology of the attached fibroblast cells on PLGA/collagen scaffold. However, the addition of BG has improved cell attachment to PLGA/collagen scaffold. As it is observed in Fig. 2c-f, the amount of attached cells has increased impressively and more area of the scaffold is covered by fibroblast cells. It could be due to nanoscale topology of the bioactive glass and increased surface area of the scaffold, which provides better situation for cell attachment (Teixeira et al. 2004; Wang et al. 2013).

Cell attachment in turn can influence proliferation and differentiation. Figure 3 indicates that better proliferation has occurred for glass-containing scaffolds. This could be 


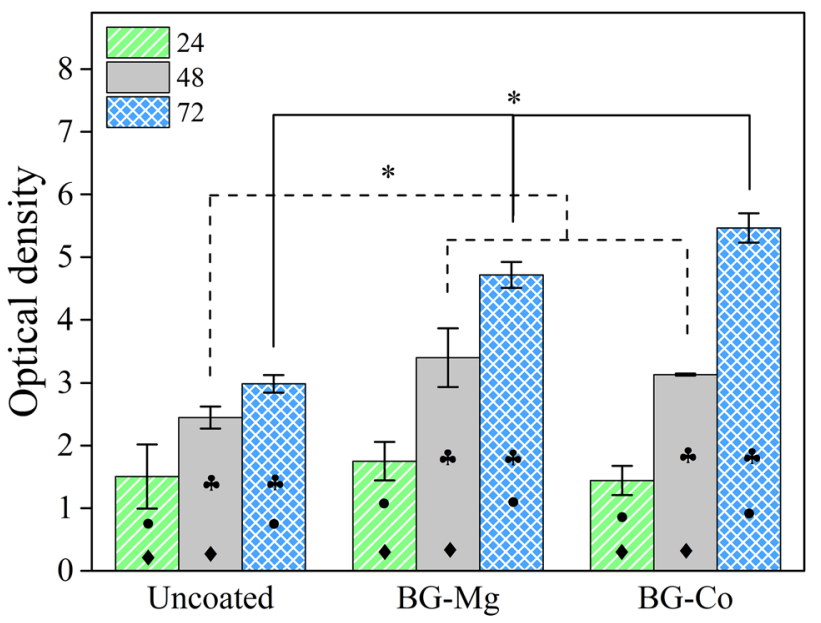

Fig. 3 MTT assay results for uncoated, BG-Mg, and BG-Co samples. Black-filled diamond indicates significant difference $(p<0.05)$ of cell viability between 24 and $48 \mathrm{~h}$. Black-filled club indicates significant difference $(p<0.05)$ of cell viability between 48 and $72 \mathrm{~h}$. Blackfilled circle indicates significant difference $(p<0.05)$ of cell viability between 24 and $72 \mathrm{~h}$. Asterisk indicates significant difference $(p<0.05)$ of cell viability between different samples

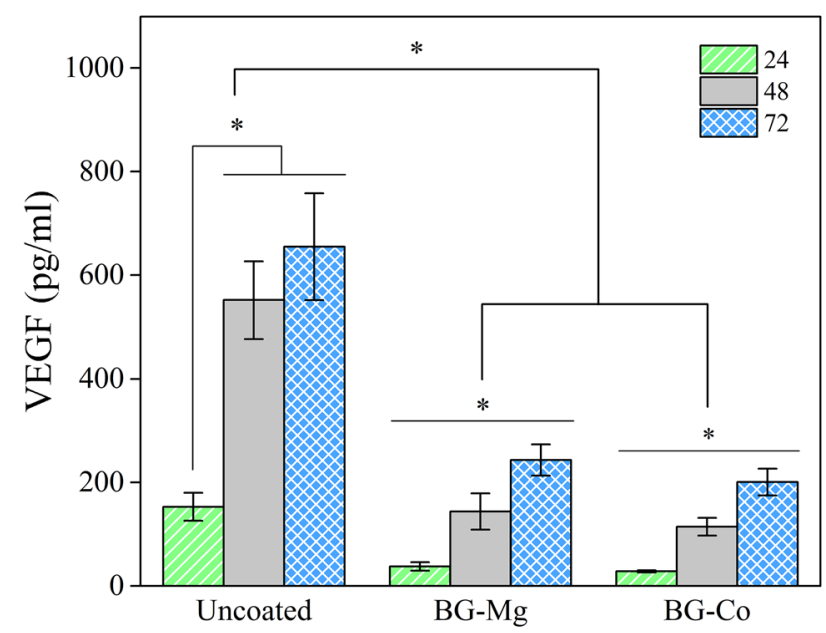

Fig. 4 Measurement of VEGF secretion by 3T3 fibroblast cells after 24,48 , and $72 \mathrm{~h}$ of cell culturing for uncoated, BG-Mg, and BG-Co samples. The asterisk indicates significant level $(p<0.05)$ of VEGF secretion

due to surface chemistry and topography. Nanotopography and nanoscale pores can improve cell proliferation (Zheng et al. 2009). Beside surface characteristics, bioactive glass can release ions which stimulate proliferation-associated signaling pathways (Hench 2009; Hoppe et al. 2011).

It has been shown that the small amount of bioactive glass enhances growth factor secretion. Gorustovich et al. have provided a comprehensive review of the effect of BG on angiogenesis (Gorustovich et al. 2010). Therefore, it is expected that the release of BG would enhance VEGF secretion from fibroblast cells for BG-containing scaffolds. Figure 4 shows that the amount of secreted VEGF is not significantly different for BG-Co and BG-Mg samples, but this value is higher for scaffold without bioactive glass. Day et al. have shown that $0.1 \%(\mathrm{w} / \mathrm{v})$ of micron-sized $\mathrm{BG}$ is suitable for increasing VEGF secretion and higher concentrations would diminish it (Day et al. 2005). In the present research, this quantity of BG has a negative effect on VEGF amount. This could be due to nanometer size and high surface area of BG particles, which promotes fast degradation and increases ionic concentration. Moreover, the bioactive glass methodical synthesis, i.e., sol-gel, makes the surface more porous compared to the melt-derived glass and, therefore, it makes it more prone to fast degradation (Sepulveda et al. 2002). Comparing uncoated sample with BG-coated samples, it is obvious that in the presence of bioactive glasses, Si concentration in culture medium has increased significantly (Fig. 5a). This is an indication of glass degradation. Moreover, it can be observed that almost all Si concentrations have incremented by the first $24 \mathrm{~h}$; in other words, bioactive glasses have degraded very fast. It seems that inhibition of VEGF secretion in BG-containing scaffolds is due to the fast and uncontrolled release of ions. Therefore, to improve angiogenesis and cell adhesion simultaneously, optimum particle size of bioactive glass should be determined. Figure 5 shows the ionic concentrations of $\mathrm{Si}, \mathrm{Ca}$, and $\mathrm{P}$ concentration in culture medium. High concentrations of $\mathrm{Ca}, \mathrm{P}$, and $\mathrm{Mg}$ ions for uncoated sample are due to inorganic salt constituents of DMEM including $\mathrm{CaCl}_{2}, \mathrm{NaH}_{2} \mathrm{PO}_{4}$, and $\mathrm{MgSO}_{4}$. During the first day, $\mathrm{Ca}^{2+}$ concentration has increased in BG-containing samples, which is due to glass degradation (Fig. 5b). However, the concentration is decreased in the following days. The reduction of ion concentration in the presence of bioactive glass is more obvious for phosphorus concentration (Fig. 5c). These observations show that $\mathrm{Ca}$ and $\mathrm{P}$ ions have been adsorbed on the surface of BG-containing scaffolds. As indicated by Hench and other researchers (Hench 1993; Hayakawa et al. 1999; Lin et al. 2005), the degradation of bioactive glass produces a hydrated silica gel layer on the surface, which provides a suitable place for $\mathrm{Ca}^{2+}$ and $\mathrm{PO}_{4}^{-3}$ deposition. The reduction of $\mathrm{P}$ concentration in culture medium for both $45 \mathrm{~S} 5$ and $58 \mathrm{~S}$ bioactive glasses has been reported by Sepulveda et al. (Sepulveda et al. 2002). Therefore, the reduction of $\mathrm{Ca}$ and $\mathrm{P}$ ion concentrations in the culture medium is attributed to the formation of a superficial gel layer on bioactive glass and its ionic adsorption characteristics.

Figure 6 shows magnesium and cobalt concentration for BG-Mg and BG-Co, respectively. Co ion is not available in DMEM and so the only source of cobalt ion is Co-doped bioactive glass. Data show that the concentration of Co ion is in its highest amount in the first day after soaking in 

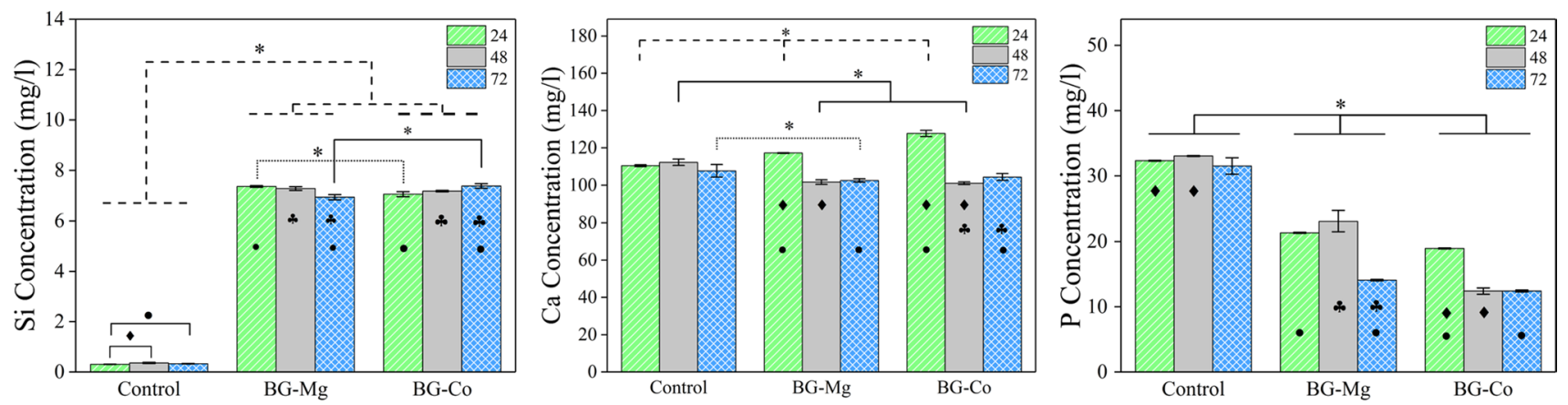

Fig. 5 ICP-OES results showing concentrations of $\mathrm{Si}, \mathrm{Ca}$, and $\mathrm{P}$ for uncoated, BG-Mg, and BG-Co samples. Data were collected after 24, 48 , and $72 \mathrm{~h}$ of soaking samples in culture medium. Black-filled diamond indicates significant difference $(p<0.05)$ of ion concentration between 24 and $48 \mathrm{~h}$. Black-filled club indicates significant differ-

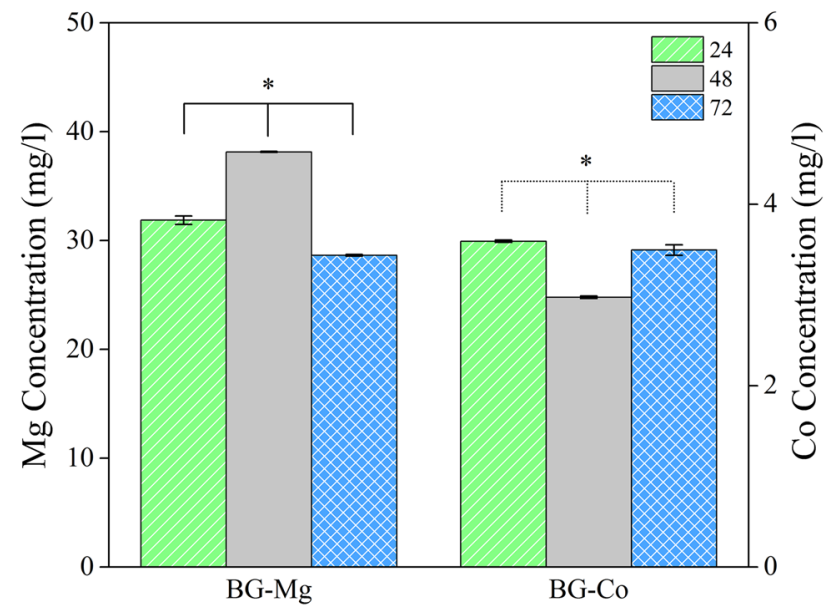

Fig. 6 Ion concentrations of $\mathrm{Mg}$ and $\mathrm{Co}$, respectively, for BG-Mg and BG-Co samples. Data were collected after 24,48 , and $72 \mathrm{~h}$ of samples soaking in culture medium

DMEM. This is another indication of fast degradation of the bioactive glass. The Co concentration is decreased in the second day and then increased. However, the magnesium ion concentration is increased until the second day and then it is decreased. The alterations in $\mathrm{Co}$ and $\mathrm{Mg}$ concentrations in different days show the unstable surface adsorption behavior of bioactive glass in the culture medium.

Also, the addition of bioactive glass has reduced contraction of the PLGA/collagen scaffold in contact with the culture medium (data not shown). Many studies have reported shrinkage of electrospun polymeric scaffolds when they are exposed to culture medium (Xie et al. 2011; Cui et al. 2012). It happens because during electrospinning process, polymer chains are exposed to a high electric field and stretched along field direction. This produces inner stress in the elongated fibers. When polymer is soaked in solution with high enough temperature, i.e., close or higher than polymer glass ence $(p<0.05)$ of ion concentration between 48 and $72 \mathrm{~h}$. Black-filled circle indicates significant difference $(p<0.05)$ of ion concentration between 24 and $72 \mathrm{~h}$. Asterisk indicates significant difference $(p<0.05)$ of cell viability between different samples

transition temperature, macromolecules acquire mobility and consequently fibers are shrunk (Ru et al. 2015). For successful implantation of skin substitutes in skin surgeries, no size alteration should happen. Moreover, dimensional instability and porosity changes of scaffold can negatively affect cell attachment and infiltration into the scaffold (Ru et al. 2015). Therefore, reducing the contraction of scaffold is another positive effect of bioactive glass addition.

\section{Conclusion}

We investigated the effect of $\mathrm{CoO}-$ or $\mathrm{MgO}$-doped 64S bioglass nanoparticles coating on PLGA/collagen composite scaffold. The analysis showed fast degradation of bioglass in culture medium. Although the concentration of $\mathrm{Si}$ and Co increased due to bioglass degradation, the concentrations of $\mathrm{P}$ and $\mathrm{Ca}$ decreased after 3 days, which was attributed to ion precipitation on bioactive glass nanoparticles. Coating of PLGA/collagen with BG nanoparticles significantly increased attachment and viability of the fibroblast cells and enhanced dimensional stability of the scaffold. However, the VEGF secretion decreased in BG-coated sample compared to the uncoated scaffold. This could be attributed to a high concentration of ions in culture medium because of nanoparticle fast degradation. Future works should determine the optimum concentration/particle size of bioactive glass nanoparticles for improving angiogenesis of PLGA/collagen scaffold.

Acknowledgements The authors also gratefully acknowledge the kind comments from Dr. Houshang Rafatpanah for angiogenesis assay and Mrs. M. Hooshyar Sadeghian for technical assistance in SEM analysis.

Funding This study was funded by ACECR (Grant number 2146-21). 


\section{Compliance with ethical standards}

Conflict of interest The authors declare that they have no conflict of interest.

Ethical approval This article does not contain any studies with human participants or animals performed by any of the authors.

Open Access This article is distributed under the terms of the Creative Commons Attribution 4.0 International License (http://creativeco mmons.org/licenses/by/4.0/), which permits unrestricted use, distribution, and reproduction in any medium, provided you give appropriate credit to the original author(s) and the source, provide a link to the Creative Commons license, and indicate if changes were made.

\section{References}

Balamurugan A, Balossier G, Kannan S et al (2007) Development and in vitro characterization of sol-gel derived $\mathrm{CaO}-\mathrm{P}_{2} \mathrm{O}_{5}-\mathrm{SiO}_{2}-\mathrm{ZnO}$ bioglass. Acta Biomat 3:255-262. https://doi.org/10.1016/j.actbi o.2006.09.005

Bellantone M, Williams HD, Hench LL (2002) Broad-spectrum bactericidal activity of $\mathrm{Ag}_{2} \mathrm{O}$-doped bioactive glass. Antimicro Agents Chemo 46:1940-1945. https://doi.org/10.1128/ AAC.46.6.1940-1945.2002

Blaker JJ, Gough JE, Maquet V et al (2003) In vitro evaluation of novel bioactive composites based on Bioglass ${ }^{\circledR}$-filled polylactide foams for bone tissue engineering scaffolds. J Biomed Mat Res Part A 67A:1401-1411. https://doi.org/10.1002/jbm.a.20055

Boccaccini A (2003) Bioresorbable and bioactive polymer/Bioglass ${ }^{\circledR}$ composites with tailored pore structure for tissue engineering applications. Compos Sci Technol 63:2417-2429. https://doi. org/10.1016/S0266-3538(03)00275-6

Bose S, Fielding G, Tarafder S, Bandyopadhyay A (2013) Understanding of dopant-induced osteogenesis and angiogenesis in calcium phosphate ceramics. Trends Biotech 31:594-605. https://doi. org/10.1016/j.tibtech.2013.06.005

Chen J-P, Chang G-Y, Chen J-K (2008) Electrospun collagen/chitosan nanofibrous membrane as wound dressing. Coll Surf A: Physicochem Eng Asp 313-314:183-188. https://doi.org/10.1016/j.colsu rfa.2007.04.129

Cui W, Cheng L, Li H et al (2012) Preparation of hydrophilic poly $(L-$ lactide) electrospun fibrous scaffolds modified with chitosan for enhanced cell biocompatibility. Polymer 53:2298-2305. https:// doi.org/10.1016/j.polymer.2012.03.039

Cui N, Qian J, Wang J et al (2016) Physicochemical properties and biocompatibility of PZL/PLGA/bioglass composite scaffolds for bone tissue engineering. RSC Adv 6:97096-97106. https://doi. org/10.1039/C6RA20781B

Day RM, Maquet V, Boccaccini AR et al (2005) In vitro and in vivo analysis of macroporous biodegradable poly $(D, L$-lactide-co-glycolide) scaffolds containing bioactive glass. J Biomed Mat Res Part A 75:778-787. https://doi.org/10.1002/jbm.a.30433

Dhandayuthapani B, Yoshida Y, Maekawa T, Kumar DS (2011) Polymeric scaffolds in tissue engineering application: a review. Int $\mathrm{J}$ Polym Sci 2011:1-19. https://doi.org/10.1155/2011/290602

Diba M, Tapia F, Boccaccini AR, Strobel LA (2012) Magnesium-containing bioactive glasses for biomedical applications. Int J Appl Glass Sci 3:221-253. https://doi.org/10.111 1/j.2041-1294.2012.00095.x
Filipowska J, Pawlik J, Cholewa-Kowalska K et al (2014) Incorporation of sol-gel bioactive glass into PLGA improves mechanical properties and bioactivity of composite scaffolds and results in their osteoinductive properties. Biomed Mat 9:065001. https:// doi.org/10.1088/1748-6041/9/6/065001

Gentleman E, Fredholm YC, Jell G et al (2010) The effects of strontium-substituted bioactive glasses on osteoblasts and osteoclasts in vitro. Biomaterials 31:3949-3956. https://doi.org/10.1016/j. biomaterials.2010.01.121

Gerhardt L-C, Boccaccini AR (2010) Bioactive glass and glassceramic scaffolds for bone tissue engineering. Materials 3:3867-3910. https://doi.org/10.3390/ma3073867

Gorustovich AA, Roether JA, Boccaccini AR (2010) Effect of bioactive glasses on angiogenesis: a review of in vitro and in vivo evidences. Tissue Eng Part B Rev 16:199-207. https://doi. org/10.1089/ten.TEB.2009.0416

Hayakawa S, Tsuru K, Ohtsuki C, Osaka A (1999) Mechanism of apatite formation on a sodium silicate glass in a simulated body fluid. J Am Cer Soc 82:2155-2160. https://doi. org/10.1111/j.1151-2916.1999.tb02056.x

Hench LL (1993) Bioceramics: from concept to clinic. Am Cer Soc Bul 72:93-98

Hench LL (2006) The story of Bioglass ${ }^{\circledR}$. J Mat Sci: Mat Med 17:967-978. https://doi.org/10.1007/s10856-006-0432-z

Hench LL (2009) Genetic design of bioactive glass. J Eur Cer Soc 29:1257-1265. https://doi.org/10.1016/j.jeurcerams oc. 2008.08 .002

Hodgkinson T, Yuan X-F, Bayat A (2014) Electrospun silk fibroin fiber diameter influences in vitro dermal fibroblast behavior and promotes healing of ex vivo wound models. J Tissue Eng 5:204173141455166. https://doi.org/10.1177/204173141455166 1

Hoppe A, Güldal NS, Boccaccini AR (2011) A review of the biological response to ionic dissolution products from bioactive glasses and glass-ceramics. Biomaterials 32:2757-2774. https ://doi.org/10.1016/j.biomaterials.2011.01.004

Imani Fooladi AA, Hosseini HM, Hafezi F et al (2013) Sol-gelderived bioactive glass containing $\mathrm{SiO}_{2}-\mathrm{MgO}-\mathrm{CaO}-\mathrm{P}_{2} \mathrm{O}_{5}$ as an antibacterial scaffold. J Biomed Mat Res Part A 101(A):15821587. https://doi.org/10.1002/jbm.a.34464

Keshaw H, Georgiou G, Blaker JJ et al (2009) Assessment of polymer/bioactive glass-composite microporous spheres for tissue regeneration applications. Tissue Eng Part A 15:1451-1461. https://doi.org/10.1089/ten.tea.2008.0203

Kumbar SG, Nukavarapu SP, James R et al (2008) Electrospun poly(lactic acid-co-glycolic acid) scaffolds for skin tissue engineering. Biomaterials 29:4100-4107. https://doi.org/10.1016/j. biomaterials.2008.06.028

Leu A, Leach JK (2008) Proangiogenic potential of a collagen/bioactive glass substrate. Pharma Res 25:1222-1229. https://doi. org/10.1007/s11095-007-9508-9

Li W-J, Laurencin CT, Caterson EJ et al (2002) Electrospun nanofibrous structure: a novel scaffold for tissue engineering. J Biomed Mat Res 60:613-621. https://doi.org/10.1002/ jbm. 10167

Li J, Chen S, Vaughn A et al (2015) Mesoporous bioactive glass surface modified poly(lactic-co-glycolic acid) electrospun fibrous scaffold for bone regeneration. Int J Nanomed 10:3815. https://doi. org/10.2147/IJN.S82543

Li X, You R, Luo Z et al (2016) Silk fibroin scaffolds with a micro-/ nano-fibrous architecture for dermal regeneration. J Mater Chem B 4:2903-2912. https://doi.org/10.1039/C6TB00213G

Lin KSK, Tseng Y-H, Mou Y et al (2005) Mechanistic study of apatite formation on bioactive glass surface using $31 \mathrm{P}$ solid-state NMR spectroscopy. Chem Mat 17:4493-4501. https://doi.org/10.1021/ cm050654c 
Liverani L, Lacina J, Roether JA et al (2018) Incorporation of bioactive glass nanoparticles in electrospun PCL/chitosan fibers by using benign solvents. Bioact Mat 3:55-63. https://doi.org/10.1016/j. bioactmat.2017.05.003

Lowery JLL, Datta N, Rutledge GCC (2010) Effect of fiber diameter, pore size and seeding method on growth of human dermal fibroblasts in electrospun poly( $\varepsilon$-caprolactone) fibrous mats. Biomaterials 31:491-504. https://doi.org/10.1016/j.biomateria 1s.2009.09.072

Miola M, Verné E (2016) Bioactive and antibacterial glass powders doped with copper by ion-exchange in aqueous solutions. Materials. https://doi.org/10.3390/ma9060405

Naseri S, Lepry WC, Nazhat SN (2017) Bioactive glasses in wound healing: hope or hype? J Mater Chem B. https://doi.org/10.1039/ C7TB01221G

Ostomel TA, Shi Q, Tsung C-K et al (2006) Spherical bioactive glass with enhanced rates of hydroxyapatite deposition and hemostatic activity. Small 2:1261-1265. https://doi.org/10.1002/smll.20060 0177

Powell H, Supp D, Boyce S (2008) Influence of electrospun collagen on wound contraction of engineered skin substitutes. Biomaterials 29:834-843. https://doi.org/10.1016/j.biomaterials.2007.10.036

Rahaman MN, Day DE, Sonny Bal B et al (2011) Bioactive glass in tissue engineering. Acta Biomat 7:2355-2373. https://doi. org/10.1016/j.actbio.2011.03.016

Rho KSS, Jeong L, Lee G et al (2006) Electrospinning of collagen nanofibers: effects on the behavior of normal human keratinocytes and early-stage wound healing. Biomaterials 27:1452-1461. https ://doi.org/10.1016/j.biomaterials.2005.08.004

Ru C, Wang F, Pang M et al (2015) Suspended, shrinkage-free, electrospun PLGA nanofibrous scaffold for skin tissue engineering. ACS Appl Mat Interf 7:10872-10877. https://doi.org/10.1021/ acsami.5b01953

Saboori A, Rabiee M, Moztarzadeh F et al (2009) Synthesis, characterization and in vitro bioactivity of sol-gel-derived $\mathrm{SiO} 2-\mathrm{CaO}-$ $\mathrm{P}_{2} \mathrm{O}_{5}-\mathrm{MgO}$ bioglass. Mat Sci Eng C 29:335-340. https://doi. org/10.1016/j.msec.2008.07.004
Sadeghi A, Nokhasteh S, Molavia M et al (2016) Surface modification of electrospun PLGA scaffold with collagen for bioengineered skin substitutes. Mat Sci Eng C 66:130-137. https://doi. org/10.1016/j.msec.2016.04.073

Sepulveda P, Jones JR, Hench LL (2002) In vitro dissolution of melt derived $45 \mathrm{~S} 5$ and sol-gel derived $58 \mathrm{~S}$ bioactive glasses. Biomed Mater Res 61:301-311

Teixeira AI, Nealey PF, Murphy CJ (2004) Responses of human keratocytes to micro- and nanostructured substrates. J Biomed Mat Res 71A:369-376. https://doi.org/10.1002/jbm.a.30089

Vargas GE, Durand Lv, Cadena V et al (2013) Effect of nano-sized bioactive glass particles on the angiogenic properties of collagen based composites. J Mat Sci M Med 24:1261-1269. https://doi. org/10.1007/s10856-013-4892-7

Wang S, Kowal TJ, Marei MK et al (2013) Nanoporosity significantly enhances the biological performance of engineered glass tissue scaffolds. Tissue Eng Part A 19:1632-1640. https://doi. org/10.1089/ten.tea.2012.0585

Wheeler TS, Sbravati ND, Janorkar AV (2013) Mechanical \& cell culture properties of elastin-like polypeptide, collagen, bioglass, and carbon nanosphere composites. Ann Biomed Eng 41:2042-2055. https://doi.org/10.1007/s10439-013-0825-3

Xie Z, Buschle-Diller G, Deinnocentes P, Bird RC (2011) Electrospun poly(D, L)-lactide nonwoven mats for biomedical application: surface area shrinkage and surface entrapment. J Appl Polym Sci 122:1219-1225. https://doi.org/10.1002/app.34239

Zheng Z, Zhang L, Kong L et al (2009) The behavior of MC3T3-E1 cells on chitosan/poly-L-lysine composite films: effect of nanotopography, surface chemistry, and wettability. J Biomed Mat Res Part A 89:453-465. https://doi.org/10.1002/jbm.a.31979

Publisher's Note Springer Nature remains neutral with regard to jurisdictional claims in published maps and institutional affiliations. 